\title{
Virtual Tourism, New Opportunities in the Tourism Sector during the Pandemic
}

\author{
Yuliana Kristanto ${ }^{1}$ \\ \{Email: yulianakristanto@lecturer.undip.ac.id\} \\ ${ }^{1}$ Public Administration Department, Universitas Diponegoro, Semarang Indonesia
}

\begin{abstract}
When the whole world experienced the Covid-19 pandemic, almost all sectors both in the public and private sectors were affected, from reducing turnover to stopping all activities. Likewise in the tourism sector, which was once one of the mainstays of both State Foreign Exchange Income and Regional Income, finally came to a halt. To solve this problem, the Ministry of Tourism and Creative Economy (Kemenparekraf) and Kemendikbud made a breakthrough by cooperating with the private sector, namely Virtual Tourism. This policy has been implemented from May until now. This study wants to determine the success rate of virtual tourism innovation by looking at the level of public interest and knowledge about this tourism innovation. The research method used in this paper is the Big Data processing method from social media, namely Instagram. From the results of the analysis, it was found that from 891 posts, not much showed the public's interest in trying Virtual Tourism.
\end{abstract}

Keywords: Pandemic, Tourism, Virtual tourism, Innovation, Big Data

\section{Introduction}

The Covid-19 pandemic (Corona Virus Disease-19) seems to be a problem facing almost all countries. This pandemic situation was able to destroy social activities, the economic sector, politics, and even education. The countries affected are implementing various strategies to contain the epidemic to efforts to reduce its impact on the country's growth. Tourism is one of the sectors that was originally the largest input provider to the country which has fallen dramatically. Tourism is a very large industrial sector and has a strategic role in supporting the country's economic growth rate. As a promising sector, many countries make tourism one of their advantages. Tourism is able to generate profits without exploiting nature.

In Indonesia, tourism occupies an important position as a source of foreign exchange. This reversed drastically during the Covid-19 pandemic that hit Indonesia from March 2020. The Indonesian Hotel and Restaurant Association (PHRI) noted that until April 2020, the total losses of the Indonesian tourism industry reached IDR 85.7 trillion. Thousands of hotels and restaurants have been forced to close, as well as a number of airlines and tour operators who have suffered losses.

Based on data from the World Tourism Organization (UNWTO), the number of tourist arrivals worldwide decreased 44 percent during the pandemic when compared to last year. In an 
online discussion early last month, the Deputy for Destination and Infrastructure Development of the Ministry of Tourism and Creative Economy (Kemenparekraf), Hari Santosa Sungkari, predicted that the visit of foreign tourists (tourists) to Indonesia would be stuck at 4 million people. If it was before Covid there was 18 million, now this year there are around 2.8-4 million tourists, which should be 18 million, "said Hari. [1]

This situation has made the government look for strategies and innovations so that the tourism sector will continue to run during this pandemic. To overcome this problem, the Ministry of Tourism and Creative Economy (Kemenparekraf) and Kemendikbud made a breakthrough by cooperating with the private sector, namely Virtual Tourism. Virtual tourism itself is a simulation of an existing location, usually consisting of a sequence of videos or still images [2]. It can also use other multimedia elements such as sound effects, music, narration, and text. [3].Virtual Travel is able to visually display tourist locations with a 360 degree panoramic view so that users can know the surroundings.

With virtual community tourism, it is shown how technology and digital media bring people to new routines and ways of life. This type of virtual tourism is paid or not. There are also tour providers who create content using virtual reality apps and tools, such as the popular Ascape on YouTube. For DKI Jakarta, Kemenkraf collaborates with related communities to present new experiences and insights about coffee and legendary coffee places in Jakarta. Meanwhile, the Ministry of Education and Culture introduced virtual tours by exploring museums and historical places.

Technology-based tourism is expected to be able to bridge the suspended animation problems with the problem of managing the pandemic. However, there is an interesting opinion poll conducted by Kompas Daily about the implementation of this Virtual Tour in Indonesia. Virtual tourism has actually been a concept that has existed for a long time in the world, first held on November 3, 1994 by presenting a reconstruction of a historic castle, Dudley Castle, in England with the aim of conserving cultural heritage. Whereas in Indonesia, virtual tourism providers have grown since 2014 and were only initiated by the Ministry in May 2020. In the results of the opinion poll, it is known that only 13.8 percent of the public are aware of virtual tourism, while the remaining 86.2 percent admit the same. do not know about this tourism innovation [4]. This Footprint was conducted from a sample age range of 18 to 50 years.

From the results of this opinion poll, the researcher wanted to know the level of public interest and knowledge in this virtual tourism concept on social media. This level of knowledge and interest is one of the conditions for the diffusion of an innovation to be successful in society.

\subsection{Theoritical Concept}

Theoretical concepts need to be discussed in this study are:

\subsubsection{Innovation Theory}

When it comes to innovation, we don't always talk about new things. Innovation can also be in the form of new methods to improve the quality / quality of an existing program or item. Innovation can be obtained through discretion, invention or renewal / improvement of a product with new methods / ways.

The innovations that have been sparked need to be disseminated / communicated. Communication is the process of sending messages from the informant / message to the recipient of the information / message using communication channels. In the dissemination of innovation it can be done by diffusion and / or dissemination. The diffusion of innovation is the process of communicating innovation through means of communication at certain times in the social system. [5] 


\subsubsection{The Innovation Decision Process}

Innovation is a new thing that requires a process in its application. This means that not all innovations can be directly accepted / adopted by the public. Innovation needs to be communicated first, then the innovation decision process, namely the process of a person / individual accepting or rejecting an innovation. According to Rogers [6], as quoted by Sa'ud, the innovation decision-making process is a mental process where a person / individual passes from the first knowledge of an innovation by forming an attitude towards innovation, until deciding to reject or accept, implement ideas. new and confirmed against innovation decisions.

The mechanism related to innovation decision making consists of five stages, namely:

- Knowledge (knowledge),

- Persuasion (persuasion),

- Decision (decision),

- Implementation (implementation),

- Confirmation (confirmation)

In this study, researchers focused on the recipient's Knowledge Innovation stage and the Persuasion stage.

a. The knowledge stage.

At this stage, a person does not have complete information about innovation. Therefore, innovation needs to be conveyed through various existing communication channels, either through electronic media, print media, or interpersonal communication among the community. It is hoped that prospective adapters will know complete information related to these innovations.

b. The persuasion stage.

At this stage, individuals are interested in innovation and actively seek detailed information about innovation. This second stage occurs more in the level of thinking of the potential user / adapter. At this stage there will be a feeling of liking or displeasing to innovation, where the feeling of pleasure or displeasure is influenced by the characteristics of the innovation itself, such as [7] :

1) the advantages of innovation,

2) compatibility level,

3) complexity,

4) can be tried and

5) can be seen

\subsubsection{Virtual Tour}

A virtual tour is a simulation of an existing location, usually consisting of a sequence of videos or still images. It can also use other multimedia elements such as sound effects, music, narration, and text. It is distinguished from the use of live broadcast or tele-tourism.

The phrase "virtual tour" is often used to describe various video and photographic media. Panorama shows an unbroken view, because a panorama can be a series of photos or panning video recordings. However, "panoramic tours" and "virtual tours" have largely been associated with virtual tours created using static cameras. The virtual tour consists of a number of photos taken from a single point of view. The camera and lens are rotated around or what is known as parallax (the point directly behind the converging lens or light).

A video tour is a full motion video of a location. Unlike static wrap-around, a video tour is a video that runs linearly through locations. Using a video camera, locations are filmed at a walking speed while moving steadily from point to point across the subject's location. [8]. 


\section{Methodology}

This research method uses Big Data processing methods or Big Data Analysis. The source of Big Data used is all posts related to virtual travel hashtags or keywords on Social media Instagram. The data obtained were 1053 posts, using a processing program, the whole data would be processed and analyzed by several categories.

\section{Finding and Discussion}

\subsection{Data Retrieval}

Results to determine the level of understanding and public interest in virtual tourism innovation, researchers entered the hashtag or the keyword Virtual Tourism in the Instagram Social Media search engine. With this particular program, researchers got 1053 posts about Virtual Tourism

Instagram

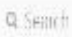

ก $\nabla \oplus Q \oplus 00$

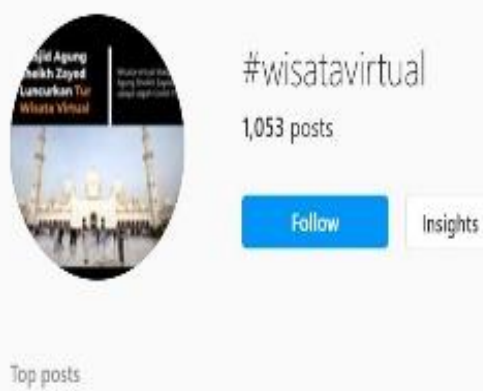

Fig 1. The number of posting data

From 1053 posts then processed with a data processing program, the following results were obtained.

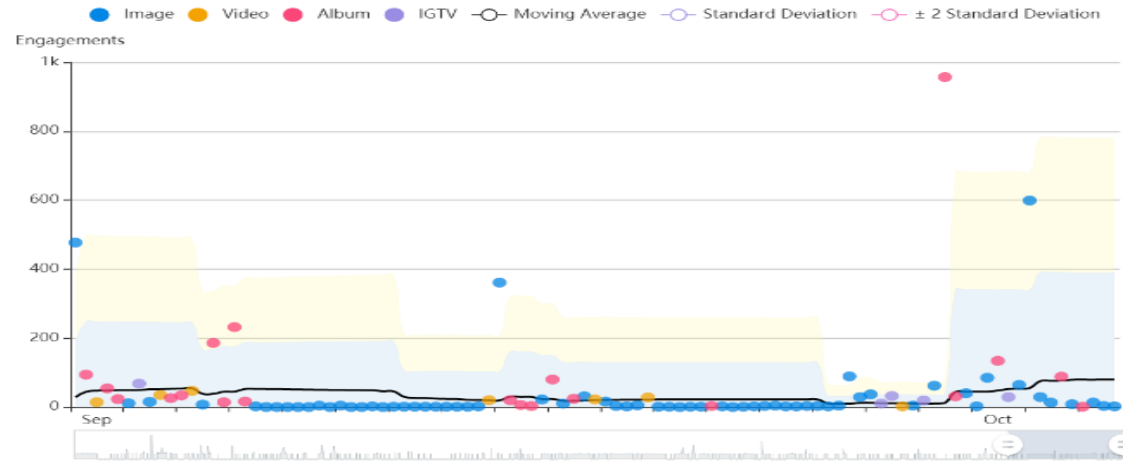

Fig 2. Post Performance

The first most popular posts and the ones that get a lot of user response are photos, not videos. If clicked, the post in question will appear, namely the image below: 
Instagram

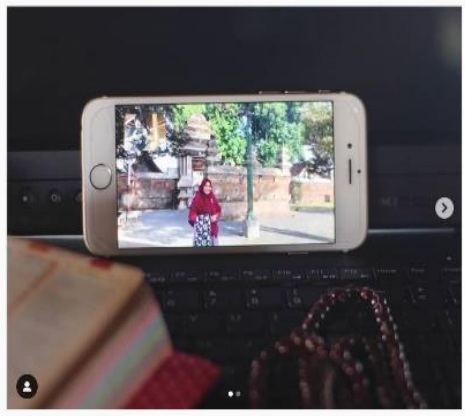

Fig 3. Post popular

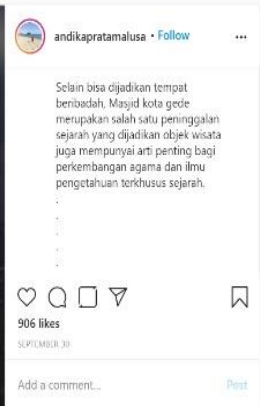

The post received a response from 906 users. Even though when viewed from the uploaded content, it is not an example of virtual tourism. This post is also not from the official Wista Virtual organizer either from the government or private sector.

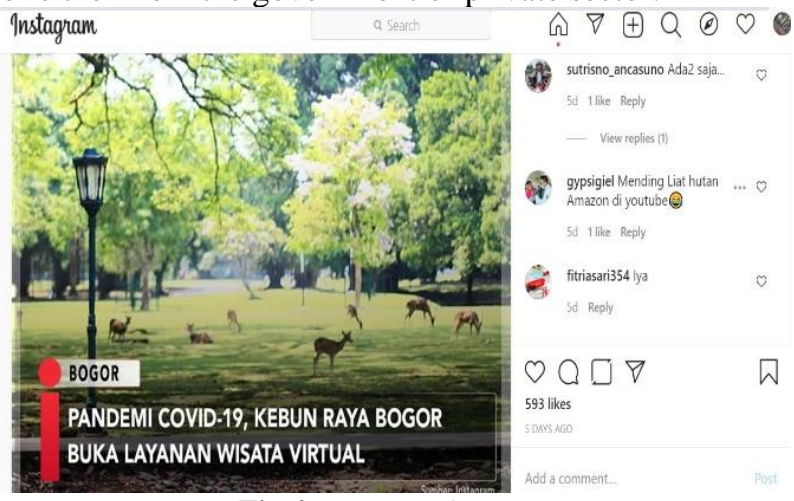

Fig 4. Post Popular

The second most popular photo on Instagram related to Virtual Tourism is a photo about the promotion of the Bogor Botanical Gardens which opens virtual tourism services. This photo received a response from 593 likes from Instagram users. However, if we look at the results of the comments, it will be seen that users are not interested and even seem to underestimate this tourism pattern.

What about the age of users who post and respond to virtual tourism in Indonesia? Following are the results of the analysis by posting time category or posting time.

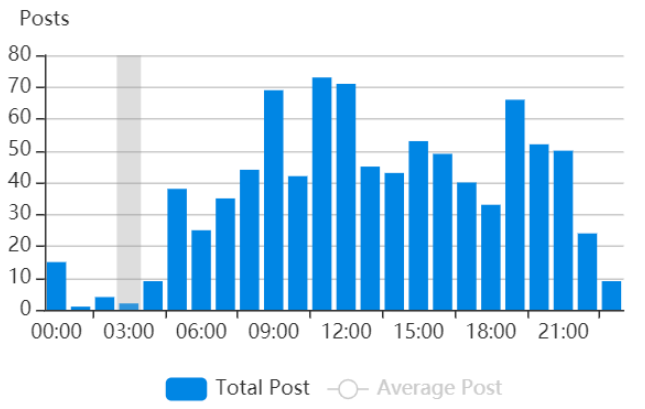

Fig 5. Posting Time 
It can be seen from the figure that the time for posting tends to spread out evenly in each hour. It can be concluded that there is age equalization for users who are interested in Virtual Tourism. Not focused on a particular age range or occupation.

\subsection{Discussion}

From the results of data retrieval, several results can be found, namely:

1 There are 1053 posts on Instagram related to virtual travel. From these results, if calculated from the Launching which has been carried out since May, it is a relatively small number. In all of these posts, they were not dominated by the socialization of the Ministry of Creative Affairs and the Ministry of Education and Culture about virtual tourism innovation in Indonesia.

2 From all of these posts, if analyzed from the time of posting, it can be concluded that the age range of IG users who post virtual tours tends to be average, from young to old and from various occupations. So that this data is in line with previous research conducted by Kompas, namely a trail of opinions to the public about the knowledge of Virtual Tourism. The opinion poll resulted in 13 percent of the public aware of the existence of Virtual Tourism in Indonesia, while the remaining 87 percent did not know and understand. All poll participants were from an unspecified age and occupation range.

3 From the graph of the most popular posts, it is found that the most popular posts and get a lot of user responses are not in fact the type of virtual tourism officially offered by the Government or tourism agencies. At this stage, someone does not have complete information about the Virtual Tourism innovation. Therefore, innovation needs to be conveyed through various existing communication channels, either through electronic media, print media, or interpersonal communication among the community. It is hoped that prospective adapters will know complete information related to these innovations.

4 The second most popular post is a post from the Bogor City Government about Bogor Botanical Gardens, which opens a virtual tourism service. From the content of user comments, it seems that the level of interest is low to follow and even seems discouraging. A comment appeared "Better to see the Amazon forest on Youtube". These comments indicate that at the persuasion stage of innovation, namely generating public interest, it is considered unsuccessful.

\section{Conclusion}

From the overall processing carried out in this research, it shows that the two stages of the innovation decision process in society, namely the level of knowledge and the level of persuasion to generate interest in the target of innovation, are considered unsuccessful. When viewed from the overall data, the researcher can provide advice to the Ministry of Creative Affairs, Kemendikbud and government authorities, to collaborate with young communities and influencers in the context of socializing safe tourism alternatives, namely Virtual Tourism. Of course, in its implementation, the government must be ready with all the required resources. 


\section{References}

[1] rap/yp, "No Title."

[2] M. Colasante, "Nicola Building Virtual Tour; Considering simulation in the equity of experience concept," in Ascilite Hobart 2011: Changing Demands, Changing Directions, 2011, pp. 263-268.

[3] D. Jan, A. Roque, A. Leuski, J. Morie, and D. Traum, "A virtual tour guide for virtual worlds," in International Workshop on Intelligent Virtual Agents, 2009, pp. 372-378.

[4] KOMPAS, "No Title," 2020.

[5] Ahmed H. Tolba;Maha Mourad, "Individual and Cultural Factor affecting Diffusion of Innovation, Journal International Business and Cultural Studies," Individ. Cult. Factor Affect. Diffus. Innov. J. Int. Bus. Cult. Stud., 2016.

[6] E. M. Rogers, Diffusion of innovations. Simon and Schuster, 2010.

[7] UIN Surabaya, "No Title," Inov. Teknol.

[8] Amay Blog, "No Title," Pengertian Virtual Tour. . 